\title{
PESQUISADORA, ETNOBIÓLOGA, LÍDER COMUNITÁRIA, GERAIZEIRA: REFLEXÕES SOBRE AS DIFICULDADES ENCONTRADAS POR DUAS MULHERES EM SUAS ATUAÇÕES EM CAMPO
}

\author{
RESEARCHER, ETHINOBIOLOGIST, COMIMUNITY LEADER, GERAIZEIRA: \\ REFLECTIONS ON THE DIFFICULTIES FOUND BY TWO WOMEN IN THEIR \\ ACTIVITIES IN THE FIELD
}

\author{
Juliana Loureiro Almeida CAMPOS ${ }^{1 *}$; Madalena Izabel Sousa FERREIRA ${ }^{2,3}$
}

\begin{abstract}
${ }^{1}$ Laboratório de Ecologia e Evolução de Sistemas Socioecológicos, Centro de Biociências, Departamento de Botânica, Universidade Federal de Pernambuco, Cidade Universitária, Recife, Pernambuco, Brasil. ${ }^{2}$ Associação Comunitária da Fazenda São Felipe, São João do Paraíso, Minas Gerais, Brasil. ${ }^{3}$ Sementes do Paraíso *loureiroju@hotmail.com
\end{abstract}

Submitted: 12/11/2020; Accepted: 09/02/2021; Published: 10/03/2021

\section{RESUMO}

O trabalho de campo realizado durante as pesquisas etnobiológicas requer contato íntimo do(a) pesquisador(a) com o(a) participante da pesquisa, seja por meio de entrevistas ou pela aplicação de métodos participativos para a coleta dos dados. Nesse sentido, em um universo em que as ideias e olhares masculinos predominam, realizar pesquisas de campo nessa área se torna uma tarefa difícil para as mulheres. Da mesma forma, o preconceito e o machismo no meio rural tornam quase inviável a presença feminina à frente de cargos de liderança em associações e movimentos rurais. A proposta desse texto é exibir os relatos de duas mulheres, uma pesquisadora e uma líder de uma comunidade tradicional geraizeira, a respeito das dificuldades enfrentadas durante suas atuações em campo. Partindo de um texto ora narrado pela pesquisadora, ora pela líder comunitária, colocamos em pauta as dificuldades enfrentadas por mulheres em suas atuações em campo e discutimos a importância da união e da parceria feminina para ocuparmos lugares de fala, de luta e de destaque dentro do universo da pesquisa etnobiológica e da liderança comunitária rural. Essas dificuldades incluem assédios, falta de segurança, falta de confiança do participante em transmitir informações, preconceito por assumir cargos de liderança e invisibilidade na tomada de decisões, as quais são pouco exploradas pela academia e pelas lideranças do meio rural e precisam ser cada vez mais postas em evidência.

PALAVRAS-CHAVE: Etnobiologia, Gênero, Machismo, Rural, Trabalho de campo.

\begin{abstract}
Fieldwork carried out during ethnobiological research requires close contact between the researcher and the research participant, either through interviews or through the application of participatory methods for data collection. In this sense, in a universe where male ideas and views predominate, conducting field research in this area becomes a difficult task for women. Likewise, prejudice and sexism in rural areas make the presence of women at the head of leadership positions in rural associations and movements almost impossible. The purpose of this text is to show the reports of two women, a researcher and a leader of a traditional breeding community, regarding the difficulties faced during their work in the field. Starting from a text now narrated by the researcher, now by the community leader, we bring the difficulties faced by women in their work in the field and discuss
\end{abstract}


CAMPOS, J. L.A; FERREIRA, M.I.S. Pesquisadora, etnobióloga, líder comunitária, geraizeira: reflexões sobre as dificuldades encontradas por duas mulheres em suas atuações em campo. Ethnoscientia v.6 n. 2, especial, 2021. DOI: 10.22276/ethnoscientia.v6i2.373

the importance of unity and female partnership to occupy places of speech, struggle and prominence within the universe of ethnobiological research and rural community leadership. These difficulties include harassment, lack of security, lack of confidence of the participant in transmitting information, prejudice for assuming leadership positions and invisibility in decision making, which are little explored by the academy and the leaders of the rural environment and need to be increasingly highlighted.

KEYWORDS: Ethnobiology, Gender, Male chauvinism, Rural, Fieldwork.

\section{INTRODUÇÃO}

As transformações sociais promoveram mudanças no sistema produtivo, trazendo a construção de novos espaços e relações de trabalho nas quais as mulheres passaram a ocupar setores que antes eram ocupados apenas pelos homens (CHIES, 2010). Na América Latina, a maior participação feminina no mercado de trabalho pôde ser vista nas últimas três décadas e esse crescimento tem sido superior ao dos homens (ABRAMO, 2004). No entanto, essas novas relações de trabalho infelizmente trazem consigo muitas ameaças e desafios a serem superados pelas mulheres, já que vivemos em um mundo onde o machismo e o sistema patriarcal são dominantes e ainda contribuem para invisibilizar o protagonismo feminino nas relações de trabalho.

Quando se trata de trabalhos que envolvem longas permanências em campo, as ameaças e desafios enfrentados por nós mulheres parecem ainda maiores, principalmente dentro da etnobiologia, área que envolve o contato direto das pesquisadoras com seus parceiros e parceiras de pesquisa. Visitar as residências, pedir licença pra entrar e conversar sobre a utilização dos recursos naturais no cotidiano pode parecer fácil, mas quando tentamos nos colocar no lugar dos moradores que nos acolhem em casa, percebemos a estranheza que deve ser receber um desconhecido procurando acessar nosso conhecimento e anotando as respostas em uma folha de papel. A sensação de estranheza parece aumentar quando se abre a porta e a pessoa que toca a campainha é uma mulher, sozinha, com mochila nas costas e prancheta na mão. "Você não é casada? Seu marido deixa você andar sozinha por aí? Você não tem medo de trabalhar com isso não?", essas e muitas outras perguntas são constantemente ouvidas e sentidas por nós. Da mesma forma, ser uma jovem mulher que ocupa um cargo de liderança em uma comunidade rural traz consigo o preconceito e o sentimento de invisibilidade, já que a grande maioria dos líderes comunitários é formada por homens.

A literatura científica a respeito das diferenças de gênero e das dificuldades enfrentadas por mulheres em suas atuações em campo aponta diversas dificuldades que 
CAMPOS, J. L.A; FERREIRA, M.I.S. Pesquisadora, etnobióloga, líder comunitária, geraizeira: reflexões sobre as dificuldades encontradas por duas mulheres em suas atuações em campo. Ethnoscientia v.6 n. 2, especial, 2021. DOI: 10.22276/ethnoscientia.v6i2.373

incluem assédios, falta de segurança, falta de confiança do participante em transmitir informações, dificuldades em assumir cargos de liderança, entre outras (MORENO, 1995; BERRY et al., 2017; FREITAS et al., 2017; SILVA et al., 2019). Essas situações são pouco exploradas pela academia, pelos movimentos camponeses e por movimentos relacionados aos povos e comunidades tradicionais. Assim, é preciso que essas questões sejam cada vez mais postas em evidência para que sejam discutidas, superadas e solucionadas.

Nesse texto, exibimos os relatos de duas mulheres a respeito das dificuldades enfrentadas em suas atuações em campo enquanto pesquisadora em etnobiologia e líder de uma comunidade tradicional geraizeira. Os geraizeiros são agricultores dos planaltos, encostas e vales do Cerrado do norte e noroeste de Minas Gerais e oeste da Bahia e a nomenclatura destas populações vem do termo "Gerais", entendido como sinônimo de Cerrado (NOGUEIRA, 2009). Possuem um modo de vida bem específico e foram reconhecidos pelo governo federal em fevereiro de 2007, a partir do Decreto $N^{\circ}$ 6.040, que instituiu a Política Nacional de Desenvolvimento Sustentável dos Povos e Comunidades Tradicionais (BRASIL, 2007).

Visando apontar as dificuldades em ser mulher e realizar trabalhos de campo na pesquisa etnobiológica e desejando evidenciar a pouca representatividade feminina junto à liderança de povos e comunidades tradicionais, nosso relato, ora narrado pela pesquisadora, ora pela líder comunitária, surge como uma proposta de diálogo acerca dos processos de invisibilidade das mulheres que buscam ocupar a liderança de comunidades tradicionais e sua autonomia enquanto pesquisadoras. Apesar das nossas diferentes origens, nossas experiências enquanto mulheres atuantes em campo se encontram e se familiarizam em diversos pontos, fato que motivou a elaboração desse relato de caso. Buscamos também colocar em pauta a importância da união e da parceria feminina para ocuparmos lugares de fala, de luta e de destaque dentro do universo da pesquisa etnobiológica e da liderança comunitária.

\section{ORIGENS DIFERENTES, OBJETIVOS SEMELHANTES}

Nossas origens e trajetórias de vida são totalmente diferentes. Uma de nós, nascida e criada em uma comunidade tradicional geraizeira conhecida como Fazenda São Felipe, localizada no município de São João do Paraíso, Minas Gerais. Casada, mãe, uma mulher de luta que desde a adolescência já se indignava com as injustiças e com a ganância do ser humano diante das questões ambientais. Filha de agricultores de uma família composta por 
CAMPOS, J. L.A; FERREIRA, M.I.S. Pesquisadora, etnobióloga, líder comunitária, geraizeira: reflexões sobre as dificuldades encontradas por duas mulheres em suas atuações em campo. Ethnoscientia v.6 n. 2, especial, 2021. DOI: 10.22276/ethnoscientia.v6i2.373

cinco filhos, cresceu ao ar livre vivendo e usufruindo dos recursos do Cerrado. Desde pequena acompanhava seu pai em reuniões da associação de sua comunidade - o pai foi um dos fundadores da associação e participava ativamente das discussões e assembleias. Também, não era por acaso. O avô paterno, agricultor e tropeiro, já lutava pelos direitos dos moradores de sua comunidade tradicional geraizeira, e por muitos anos foi presidente da associação de moradores da fazenda São Pedro, também localizada no município de São João do Paraíso, Minas Gerais. Os exemplos e esforços dos homens de sua família, exemplos de guerreiros, e seu amor pela natureza, fê-la cursar e se formar em Ciências Biológicas. Viu de perto o plantio de grandes monoculturas de eucalipto por empresas siderúrgicas e suas ameaças às águas e à biodiversidade da região. A indignação cresceu e a tornou líder comunitária, assim como o avô e o pai. Aos 22 anos, candidatou-se ao cargo de presidenta da associação de sua comunidade rural e conseguiu ser eleita.

A outra de nós, nascida e criada na capital mineira, saiu cedo da casa dos pais para também cursar Ciências Biológicas. Formou-se mestre e doutora realizando trabalhos na área de etnobiologia junto a povos e comunidades tradicionais. Foi em uma dessas oportunidades que nos conhecemos, era um trabalho de campo fruto de uma consultoria técnica especializada. $\mathrm{O}$ trabalho estava sendo realizado no território da cidadania Alto Rio Pardo, norte de Minas Gerais e consistia em entrevistar extrativistas da região para investigar a cadeia produtiva de alguns frutos do Cerrado. Foi proposto que as entrevistas fossem realizadas por nós duas, uma vez que a líder comunitária era uma pessoa de influência na região. Ela entrou como parceira na pesquisa, hospedando a pesquisadora na casa de sua família durante a semana de reconhecimento das comunidades da região e aplicação de entrevistas piloto. Tal parceria foi crucial para que convivêssemos juntas durante todo o trabalho de campo.

Nós duas tínhamos muitas entrevistas para fazer e muitas comunidades rurais seriam visitadas, incluindo comunidades geraizeiras e quilombolas. Precisaríamos da ajuda uma da outra, mas não seria possível trabalhar juntas sempre: haveria momentos em que estaríamos sozinhas em campo. A percepção de tal fato nos fez compartilhar nossas histórias, mas também nossos medos e inseguranças com muita sinceridade. Os diálogos aconteciam durante e após o trabalho de campo, estreitando cada vez mais nossa parceria na pesquisa e consequentemente nossa amizade. Não passamos por nenhuma situação constrangedora enquanto trabalhávamos juntas, mas apesar de nossas origens e trajetórias de vida serem totalmente diferentes, percebemos que os desafios que enfrentávamos constantemente tinha origem no sistema patriarcal que nos foi imposto. O machismo, fruto desse sistema, nos 
CAMPOS, J. L.A; FERREIRA, M.I.S. Pesquisadora, etnobióloga, líder comunitária, geraizeira: reflexões sobre as dificuldades encontradas por duas mulheres em suas atuações em campo. Ethnoscientia v.6 n. 2, especial, 2021. DOI: $\underline{10.22276 / \text { ethnoscientia.v6i2.373 }}$

inibe enquanto mulheres, provocando situações cujo objetivo é impedir nossa independência e autonomia, principalmente à autonomia profissional.

\section{DIFICULDADES ENFRENTADAS POR MULHRES EM ATUAÇÕES EM CAMPO}

\subsection{A liderança comunitária feminina e seus desafios}

As reuniões da associação da comunidade São Felipe aconteciam uma vez por mês, aos domingos, nas quais eram discutidos problemas que acometiam a comunidade. Eu era a única mulher na atuação da diretoria da associação. De forma geral, poucas são as mulheres da minha comunidade interessadas em participar de reuniões e engajar nas lutas sociais e ambientais da nossa região. A grande maioria delas se torna mãe cedo e deixa os estudos, assumindo exclusivamente as tarefas de casa e o cuidado dos filhos. Nesse sentido, ser mulher à frente da luta comunitária sempre causou estranheza à grande maioria dos moradores e moradoras de São Felipe e nunca existiram discussões a respeito das diferenças de papéis ocupados por homens e mulheres no meio rural.

Uma das problemáticas discutidas em todas as reuniões era a questão da falta de água e a seca das nascentes localizadas no território da comunidade, relacionadas com o desmatamento. A luta pela defesa das nascentes e do Cerrado passou a ocupar quase a totalidade da minha rotina. Procurei a secretaria municipal do município para que houvesse uma visita técnica de algum órgão ambiental, mas não me atenderam. Protocolei então um ofício no Ministério Público solicitando que o município resolvesse o problema em questão. Passados mais de dois anos, após várias tentativas de conversa com o promotor, a prefeitura foi notificada a comparecer em uma reunião em que também notificaram a empresa responsável pelos eucaliptos plantados próximos às nascentes da comunidade. Durante esse período, recebi uma ameaça. Isso pode não ter relação nenhuma com o fato que foi exposto anteriormente, mas a questão é que não somente eu, como também minha família, ficamos muito apreensivos. Após esse ocorrido, meus familiares pediram para que eu não andasse mais sozinha na comunidade.

De fato, o receio de andar sozinha pela comunidade havia surgido, uma vez que no meio rural as mulheres não têm esse costume. Com isso, a falta de segurança é uma dificuldade a ser enfrentada, pois infelizmente nossa exposição pode gerar assédios por parte dos homens. Ter sempre que buscar uma companhia masculina não deveria ser uma obrigação. Mas, em pesquisas de campo no mundo em que vivemos, andar em duplas, trios 
CAMPOS, J. L.A; FERREIRA, M.I.S. Pesquisadora, etnobióloga, líder comunitária, geraizeira: reflexões sobre as dificuldades encontradas por duas mulheres em suas atuações em campo. Ethnoscientia v.6 n. 2, especial, 2021. DOI: 10.22276/ethnoscientia.v6i2.373

ou grupos, sempre acompanhada de pelo menos um homem acaba sendo a solução para evitar problemas como esse.

Os mecanismos de construção da identidade costumam estar relacionados a aspectos profundos que caracterizam os modos de ser e viver que operam em uma sociedade. Tais mecanismos, ao fim, são uma forma de retificação de algo que é parte do conjunto de ideias e representações que diferenciam essa sociedade e fazem parte de sua história (FREITAS, 2013). No meio rural, apesar da participação feminina em movimentos sociais camponeses ter sido intensificada na década de 1980 (CARNEIRO, 1994), muitos ainda são os desafios a serem superados pelas lideranças femininas dentro de um cenário patriarcal. Até 1980, a inserção das mulheres nos movimentos sociais no campo era realizada, normalmente, por meio da participação dos respectivos maridos ou de outros familiares nesses movimentos (CARNEIRO, 1994). A liderança se firma com a morte do marido, fato que conduz a mulher a substituí-lo, assumindo, então, o compromisso com a luta, numa demonstração de capacidade de liderança e de coragem desproporcionais à imagem que a sociedade lhe atribuía: aquela que deve ficar em casa, cuidar dos filhos e obedecer às ordens (do marido ou do pai).

Entre as situações enfrentadas por estar trabalhando ou liderando uma associação comunitária estão a desconfiança e o descrédito, pois uma jovem mulher não poderia estar à frente de uma associação que tem, por maioria, homens como sócios. Falta muito apoio por parte dos homens e até mesmo por outras mulheres da comunidade. Outra questão que nos afeta é o tom de voz que deve ser usado para alcançar a visibilidade das pessoas e conseguir transmitir a mensagem que desejamos passar. Ser uma mulher jovem e mãe só aumentam as dificuldades do trabalho de liderança, pois sair de casa sem a companhia de uma figura masculina ao lado não é bem-visto pelos moradores da comunidade. O direito de ir e vir é ameaçado pelos olhares que insistem em nos julgar e nos colocar em um lugar de menosprezo. A partir dessas considerações a respeito das novas relações laborais, pode-se ressaltar que a dinâmica do mercado de trabalho no meio rural vai acompanhar essa nova fase da agricultura, especialmente no que tange à mulher (ROSSINI, 1993).

\subsection{Ameaças e dificuldades de uma etnobióloga em campo}

Da mesma forma como foi abordado pela líder comunitária, o medo e a insegurança se apresentam como enormes ameaças para pesquisadoras em etnobiologia, uma vez que episódios de assédio ocorrem com frequência durante o nosso trabalho de campo. Apesar de conhecer tais ameaças e sempre ter sido questionada pelas pessoas das comunidades a 
CAMPOS, J. L.A; FERREIRA, M.I.S. Pesquisadora, etnobióloga, líder comunitária, geraizeira: reflexões sobre as dificuldades encontradas por duas mulheres em suas atuações em campo. Ethnoscientia v.6 n. 2, especial, 2021. DOI: 10.22276/ethnoscientia.v6i2.373

respeito do meu estado civil e da minha coragem por viajar para longe de casa durante as minhas pesquisas, eu nunca havia sentido medo de fazer trabalho de campo sozinha. Costumava usar roupas mais largas, estava sempre de calça, sapatos fechados e blusas que cobriam os ombros. Até que em um desses trabalhos, os quais eram realizados sempre junto de colegas homens e mulheres de meu laboratório de pesquisa, precisei ir sozinha, pois não tinha companhia para a data que deveria estar em campo. Tudo parecia bem, pois meu ajudante de pesquisa e morador da comunidade rural já me acompanhava fazia algum tempo, eu confiava nele. No entanto, sofri assédio quando nós dois estávamos a sós.

Depois do episódio, muita coisa mudou. Eu não pude comentar o ocorrido com ninguém da comunidade, pois não queria causar problemas para a família dele, a qual eu conhecia e que me tratava muito bem. Na ocasião, eu estava hospedada na casa de campo que o nosso grupo de pesquisa havia alugado na comunidade para facilitar a logística do nosso trabalho. Por medo de continuar sozinha e receber a visita do agressor em casa - que mais tarde fiquei sabendo que estava me perseguindo - acabei pedindo para uma família conhecida me hospedar até que os meus/minhas colegas chegassem na comunidade para realizarem os seus respectivos trabalhos de campo.

O fato acabou causando uma grande repercussão no laboratório de pesquisa do qual eu fazia parte na época. As mulheres foram proibidas de fazerem seus trabalhos de campo sozinhas e a orientação era para que tomássemos bastante cuidado durante as nossas viagens. No entanto, os homens continuavam a ter autonomia e independência em suas viagens de coleta de dados e isso certamente me gerou uma sensação de impotência e frustração. Além disso, a situação gerou traumas e reflexões que acabaram por prejudicar um pouco o andamento do meu trabalho acadêmico. Não poderia mais pensar em ir a campo sozinha e teria que depender sempre dos meus colegas da pós-graduação. Tinha medo de andar pela comunidade. Além disso, tive que lidar com a presença do ajudante até o final do meu trabalho de campo, pois ele conhecia muito sobre o desenho amostral da minha pesquisa e eu não teria mais tempo de conseguir outro ajudante.

Ao conversar com outras colegas pesquisadoras, percebi que o medo do assédio em campo não era algo tão raro assim. Uma pesquisa realizada com mulheres etnobiólogas a respeito da representatividade feminina na academia revelou que 62,3\% das entrevistadas já se sentiram prejudicadas durante seu trabalho de campo pelo fato de serem mulheres (SILVA et al., 2019). Entre as principais desvantagens enfrentadas pelas entrevistadas estão: dificuldade de acesso à informação e às pessoas, desvalorização, assédio e fatores estes relacionados à falta de confiança dos participantes da pesquisa em fornecer 
CAMPOS, J. L.A; FERREIRA, M.I.S. Pesquisadora, etnobióloga, líder comunitária, geraizeira: reflexões sobre as dificuldades encontradas por duas mulheres em suas atuações em campo. Ethnoscientia v.6 n. 2, especial, 2021. DOI: 10.22276/ethnoscientia.v6i2.373

informações às mulheres. De acordo com Silva et al., (2019), tais fatores podem estar associados ao patriarcado e ao sexismo recorrentes nas comunidades visitadas pelas pesquisadoras entrevistadas.

O fato de ser mulher solteira ou casada, por exemplo, também parece interferir na construção das relações de gênero durante o trabalho de campo. Devido à necessidade de contornar tais ameaças e avançar com a pesquisa, adotamos diferentes estratégias para garantir nossa segurança. Ertuğ (2013), por exemplo, relata que, apesar de estar divorciada quando foi para a aldeia em que fez sua pesquisa de campo em etnoarqueologia, decidiu não contar a ninguém que era solteira, pois chegou a ouvir que algumas pessoas poderiam presumir que ela era uma mulher livre e a assediar, enquanto outras poderiam pensar que uma mulher divorciada não era digna de respeito.

Situações desagradáveis como o emprego de frases abusivas e inconvenientes acabam por se tornar corriqueiras. Estas situações de violência extrema nos colocam medo e nos deixam receosas. Ser mulher, pesquisadora, líder comunitária se difere muito do "normal". Para Freitas et al., (2017), o medo de que episódios não incomuns de assédio possam desencadear alguma situação de violência extrema é um elemento central que deve ser levado em conta, fazendo com que não estarmos sozinhas durante o campo seja uma das nossas principais estratégias de segurança.

\section{COMO PODEMOS MUDAR ESSE CENÁRIO?}

Acreditamos que a principal solução para os desafios apontados nesse trabalho seria transformar a presença feminina no trabalho de campo em algo natural. $\mathrm{O}$ assédio e a violência sexual não deveriam ser ameaças. O estabelecimento de condições iguais entre os gêneros é algo urgente e necessário. De acordo com Lisboa (2008), reconhecer e tratar o assunto com seriedade é um caminho para diminuir a invisibilidade feminina, olhando de forma mais atenta e crítica para situações que são enfrentadas por professoras, pesquisadoras, profissionais, estudantes e/ou cientistas mulheres. No entanto, apesar de desejável, essa situação ainda parece estar distante, o que nos permite apontar algumas sugestões e estratégias que podem ser postas em prática para amenizar os desconfortos das mulheres em seus trabalhos de campo.

A formação de equipes de pesquisa compostas por homens e mulheres é sugerida por Pfeiffer e Butz (2005) como forma de amenizar situações em que o acesso à informação se apresenta como um desafio no trabalho de campo por possíveis normas culturais existentes na comunidade que podem dificultar a interação entre os gêneros. Por um lado, 
CAMPOS, J. L.A; FERREIRA, M.I.S. Pesquisadora, etnobióloga, líder comunitária, geraizeira: reflexões sobre as dificuldades encontradas por duas mulheres em suas atuações em campo. Ethnoscientia v.6 n. 2, especial, 2021. DOI: 10.22276/ethnoscientia.v6i2.373

trabalhar com a companhia de um colega pesquisador pode oferecer maior segurança e evitar situações de violência em campo que acometem nós, mulheres. Por outro lado, conforme argumentam Berry et al., (2017), as soluções reformistas silenciam os antagonismos estruturais que originam tais problemas e geram uma contradição, uma vez que clamamos por proteção, por exemplo, mas ao mesmo tempo queremos ter a liberdade de poder sair sozinhas sem medo de que algo muito ruim aconteça.

Para Freitas et al., (2017), os padrões acadêmicos vigentes ignoram o assédio e a violência sexual como uma questão mais ampla, isolando-os como problemas específicos da mulher. Para as autoras, é essencial que estas questões sejam tratadas pela comunidade acadêmica de forma geral, em cursos e seminários, por exemplo, e não fiquem somente restritas a grupos de mulheres, por mais importantes que estes sejam (FREITAS et al., 2017).

Dessa forma, é importante que os homens, tanto cientistas como membros de comunidades rurais, também discutam os assuntos relacionados aos preconceitos e ameaças sofridos pelas mulheres e apontados nesse relato. Na academia, é urgente que os pesquisadores se apropriem de espaços de discussão em congressos, promovam seminários e realizem pesquisas que tenham como tema as desigualdades de gênero, uma vez que esse discurso não deve ser promovido apenas pelas pesquisadoras. No meio rural, sugerimos que grupos de mulheres sejam formados e incentivados e que estes promovam espaços de discussão que envolvam essa temática. Temas como machismo e violência da mulher devem ser discutidos, possibilitando que as mulheres do campo conheçam suas possibilidades e se apropriem de suas capacidades de escolha. Da mesma forma, acreditamos ser de fundamental importância que esses espaços sejam organizados e realizados nas reuniões das associações, bem como nos eventos organizados pelos movimentos de luta, como é o caso, por exemplo, da Conferência Geraizeira. Promovida por diversas instituições que atuam junto aos povos e comunidades tradicionais do norte de Minas Gerais, como, por exemplo, o Movimento Geraizeiro, o Centro de Agricultura Alternativa do Norte de Minas Gerais, o Instituto Chico Mendes de Conservação da Biodiversidade, entre outros, o evento tem como objetivo compartilhar experiências e denúncias relacionadas à violação de direitos, avaliar a situação atual das lutas por território e água, refletir sobre a importância das águas do Cerrado e debater propostas de regularização fundiária dos territórios frente ao marco legal de povos e comunidades tradicionais (ICMBio, 2018). 


\section{CONSIDERAÇÕES FINAIS}

Pensando nas diversas situações de enfrentamento nas comunidades e tendo em vista os preconceitos pelos quais sofremos por sermos mulheres em campo, notamos uma melhoria ao comparar o passado ao presente. No entanto, a situação está longe de se adequar ao que chamamos de ideal. Nesse sentido, esperamos que esse relato seja lido por mulheres, mas principalmente por homens, uma vez que o machismo e as diferenças de gênero só serão combatidos quando os homens também se apropriarem desse discurso e debaterem tais temas no intuito de transformar essa realidade. Tendo em vista que outras áreas de pesquisa além da etnobiologia também executam trabalhos de campo, desejamos que esse texto auxilie as reflexões acerca das situações abordadas e que estas sejam cada vez mais debatidas em eventos científicos de forma geral.

\section{REFERÊNCIAS BIBLIOGRÁFICAS}

ABRAMO, L. ¿Inserción laboral de las mujeres en América Latina: una fuerza de trabajo secundaria? Revista Estudos Feministas, Florianópolis, v. 12, n. 2, p. 224-235, 2004.

BERRY, M. J. et al. Toward a fugitive anthropology: gender, race, and violence in the field. Cultural Anthropology, Arlington, v. 32, n. 4, p. 537-565, 2017.

BRASIL. Presidência da República, Decreto ${ }^{\circ} 6.040$ de 7 de fevereiro de 2007, que Institui a Política Nacional de Desenvolvimento Sustentável dos Povos e Comunidades Tradicionais, 2007.

CARNEIRO, M. J. Mulheres no campo: notas sobre sua participação política e a condição social do gênero. Estudos Sociedade e Agricultura, Rio de Janeiro, v. 2, n. 1, p. 11-22, 1994.

CHIES, P. V. Identidade de gênero e identidade profissional no campo de trabalho. Revista Estudos Feministas, Florianópolis, v. 18, n. 2, p. 507-528, 2010.

ERTUĞ, F. Being a woman researcher in an Anatolian village. Journal of Ethnobiology and Ethnomedicine, Londres, v. 9, Article number 45, 2013.

FREITAS, C. C. M. Entre wiphalas, polleras e ponchos: Embates entre os discursos de CONAMAQ, do Estado Plurinacional da Bolívia e do Direito Internacional. 2013. 270 f. Tese (Doutorado em Antropologia Social), Faculdade de Filosofia, Letras e Ciências Humanas, Universidade de São Paulo, São Paulo, 2013. 
FREITAS, C. C. M. et al. Campo, gênero e academia: notas sobre a experiência de cinco mulheres brasileiras na Bolívia. Cadernos de Campo São Paulo, São Paulo, v. 26, n. 1, p. 348-369, 2017.

INSTITUTO CHICO MENDES DE CONSERVAÇÃO DA BIODIVERSIDADE. Água e Território é o tema da $5^{\circ}$ Conferência Geraizeira. ICMBio, 2018. Disponível em: $<$ https://www.icmbio.gov.br/portal/ultimas-noticias/20-geral/9569-agua-e-territorio-e-otema-da-5-conferencia-geraizeira>. Acesso em: 04 fev. 2021.

LISBOA, C. Os desafios de ser mulher e trabalhar com conservação em campo. O Eco. 2018. Disponível em: <https://www.oeco.org.br/reportagens/os-desafios-de-ser-mulher-etrabalhar-com-conservacao-emcampo/>. Acesso em: 22 out. 2020.

MORENO, E. Rape in the field: reflections from a survivor. In: KULICK, D.; WILLSON, M. (Orgs.). Taboo: sex, identity and erotic subjectivity in anthropological fieldwork. 1. ed. London: Routledge, 1995. p. 166-189.

NOGUEIRA, M. Gerais a dentro e a fora: identidade e territorialidade entre Geraizeiros do Norte de Minas Gerais. 2009. 233 f. Tese (Doutorado em Antropologia), Departamento de Antropologia, Universidade de Brasília, Brasília, 2009.

PFEIFFE, M. J.; BUTZ, R. J. Assessing cultural and ecological variation in ethnobiological research: the importance of gender. Journal of Ethnobiology, Boston, v. 25, n. 2, p. 240278, 2005.

ROSSINI, R. E. Geografia e gênero: a mulher como força de trabalho no campo. Informações Econômicas, São Paulo, v. 23, n. supl. 1, p.1-13, 1993.

SILVA, T. C. et al. The role of women in Brazilian ethnobiology: challenges and perspectives. Journal of Ethnobiology and Ethnomedicine, Londres, v. 15, Article number 44, 2019. 